\title{
Antibiotic Resistance Pattern of Uropathogens among Non Pregnant Women: A Hospital based Cross Sectional Study from Odisha
}

\author{
Jyoti Ranjan Mohanty ${ }^{1,2}$, Alisha Pradhan ${ }^{3}$, Sunita Jena ${ }^{4}$, Bijaya Kumar Padhi ${ }^{5}$ (D), \\ Padmalaya Das $^{6}$ (D) and Dhananjay Soren ${ }^{1,2 *}$ (D) \\ ${ }^{1}$ Department of Zoology, Ravenshaw University, Cuttack - 753 003, Odisha, India. \\ ${ }^{2}$ Centre for Excellence in Environment and Public Health, Ravenshaw University, \\ Cuttack - 753 003, Odisha, India. \\ ${ }^{3}$ National Health Mission, Annex Building, State Institute of Health and Family Welfare, \\ Unit-8, Bhubaneswar - 751 012, India. \\ ${ }^{4}$ All India Institute of Medical Science, Bhubaneswar - 751 019, Odisha, India. \\ ${ }^{5}$ Department of Community Medicine and School of Public Health, Post Graduate Institute \\ of Medical Education \& Research, Chandigarh - 160 012, India. \\ ${ }^{6}$ School of Biological Sciences, AIPH University, Bhubaneswar - 752 101, Odisha, India.
}

\begin{abstract}
Urinary tract infection (UTI) is one of the most delicate health problem affecting women with severe complications and the rising antimicrobial resistance exerts a massive influence in treating UTIs. The objectives of this study was to identify the uropathogens causing UTI in non-pregnant women and their antibiotic resistance pattern. The study was undertaken in the outpatient department (OPD) of Obstetrics and Gynaecology, Capital Hospital, Bhubaneswar, Odisha during April 2015 to March 2016. A total of 766 midstream urine samples (MSU) was collected from women of different age. Out of 766 urine samples, $323(42.1 \%)$ samples were culture positive for UTI with prominent bacteriuria. E.coli was found to be the most common isolate (54.79\%) followed by Staphylococcus sp. (22.6\%), Enterobacter sp. (17.64\%) and Klebsiella sp. (4.95\%). Amongst various clinical symptoms, burning and itching during urination was found to be the most common $(69.97 \%)$ symptoms followed by abnormal discharge of the vagina $(45.20 \%)$ and the presence of cloudy urine (24.46\%). E.coli the most predominant uropathogen identified was found to be highly susceptible towards a low level of resistance towards nitrofurantoin (11.8\%) followed by amikacin $(\mathbf{2 0 . 0 3 \% )}$ and gentamicin $\mathbf{2 2} .0 \%)$. Our study revealed that $E$. coli isolates were the predominant uropathogens and showed escalating model of resistance to the general available antimicrobial agents which are frequently used by the physicians in hospitals and private practice.

Keywords: Urinary Tract Infections, Antibiotic resistance, Uropathogens, Bacteriuria, Anti Microbial agents
\end{abstract}

*Correspondence: dsoren@ravenshawuniversity.ac.in

(Received: August 15, 2021; accepted: December 13, 2021)

Citation: Mohanty JR, Pradhan A, Jena S, Padhi BK, Das P, Soren D. Antibiotic Resistance Pattern of Uropathogens among Non Pregnant Women: A Hospital based Cross Sectional Study from Odisha. J Pure Appl Microbiol. 2022;16(1):296-304. doi: 10.22207/JPAM.16.1.18

(C) The Author(s) 2022. Open Access. This article is distributed under the terms of the Creative Commons Attribution 4.0 International License which permits unrestricted use, sharing, distribution, and reproduction in any medium, provided you give appropriate credit to the original author(s) and the source, provide a link to the Creative Commons license, and indicate if changes were made. 


\section{INTRODUCTION}

Urinary tract infection are the major public health concern caused by various bacterial species, such as most commonly by gram-negative Escherichia coli, gram-positive Bacilli Enterococcus faecalis, gram-negative Enterobacterales Proteus mirabilis, gram-negative facultative anaerobe Klebsiella pneumoniae and gram-positive Firmicutes Staphylococcus saprophyticus. High rates of recurrence with antimicrobial resistance among uropathogens continue to increase the economic burden of infections in population, considerably. Worldwide, there are 150 million cases per annum and in excess global economic costs for 6 billion US dollars. ${ }^{1}$

Infections in the urinary tract are a frequent cause of health care visits. UTIs are the least identified area of research as the primary cause of morbidity among infants, childrens, older men and females of all ages. Irrespective of such evidences, further researches had proven that prevalence of UTI is higher among the female. ${ }^{2}$ Linhares et $\mathrm{al}^{3}$ reported that at least once in a lifetime urinary tract infection is experienced by $50 \%$ of women ${ }^{3}$ and recurrent episodes have been observed between $20 \%$ and $40 \%$ of women ${ }^{4}$ whereas all UTIs reported in men were $20 \%$ approximately. Infectious diseases are one of the most common public health issues in developing countries like India. ${ }^{6}$ In clinical practice, urinary tract infection is known for its infectious nature of the diseases etiology. ${ }^{7}$ Symptoms showing for urinary infection are usually termed as bacteriuria, ${ }^{8}$ where lower and upper urinary tracts can be affected with UTI. Lower UTI infections termed as cystitis shows several symptoms which include dysuria, frequent urgency, and suprapubic tenderness. However, in most UTI cases upper UTI is often found with lower urinary tract symptoms. ${ }^{9}$ Pregnancy, sexual activities and unhygienic practices are primary causative factors for UTI which make females more prone to this disease..$^{10}$ In non-pregnant women's uterus is placed above the bladder, and in pregnant condition the enlargement of the uterus often affects the urinary tract. ${ }^{11}$ Bacteria involved in introducing complicated UTI are with broader species than those causing uncomplicated UTI, ${ }^{12}$ whereas non-complicated UTIs are results of infection primarily due to $E$. coli, associated with bacterial pathogens like Staphylococcus sp.,
Klebsiella sp. and Proteus mirabilis. ${ }^{13}$ Escherichia coli is responsible for community-acquired UTIs of about $80-85 \%$ whereas $5-10 \%$ by the Staphylococcus saprophyticus. ${ }^{14}$

Treatment for urinary tract infections is often started with antimicrobial therapy which is based on the information of antimicrobial resistance pattern displayed by the uropathogens. ${ }^{15}$ As a result, worldwide antimicrobial resistance is found to be more prevalent among urinary pathogens. ${ }^{16,14}$ Gaining knowledge of resistance pattern and collecting information regarding susceptibility, nature of urinary pathogens towards different antibiotics varies with their distribution in a different region. Thus, it is essential to have knowledge of the distribution of these pathogens and their susceptibility pattern towards different antibiotics in a particular location with proper setting. ${ }^{17}$

The research on resistance of uropathogens isolated from non pregnant women having UTIs has not yet been reported in Odisha, India. Therefore, the current research was undertaken in view of the scarcity of reports of UTIs in non pregnant women in the state of Odisha, India. The study reveals the most common causative microorganism responsible for UTI in non-pregnant women of different age groups, with its prevalence for UTI as well as the antimicrobial resistance pattern of uropathogens.

\section{MATERIALS AND METHODS Study Settings}

The cross-sectional study was conducted at the Department of Obstetrics and Gynaecology (O\&G), Capital Hospital, Bhubaneswar, Odisha during April 2015 to March 2016.

\section{Study subjects}

The participants were recruited from women who attended the outpatient department of Obstetrics \& Gynaecology with problems related to UTI. The study subjects enrolled were of non-pregnant women aged between 20-60 years. Participants reported with UTI symptoms i.e. itching and burning during urination, urge of frequent urination, urine with cloudy or blood were included in our study with proper consent towards participation. Women with pregnancy associated with reproductive tract malignancies who had been treated with antibiotics during the 
previous three weeks of their visit, and women who denied the consent towards participation had been excluded.

\section{Sample collection}

The work presented is a part of a large study entitled "Life course approach for exploring the impact of sanitation and menstrual hygiene management on psychosocial stress, behaviour, and health among girls, women, and neonates in Odisha (Orissa), India". This cross-sectional study was designed by keeping $80 \%$ power at $5 \%$ level of significance. A total of 766 clinical patients reported to the OPD had been enrolled as study participants. The mid-stream urine sample were collected from patients suspected clinically for urinary tract infection. The clean catch sample was collected aseptically in a wide mouth sterile container followed by transportation to the microbiology laboratory for further analysis and processing within 15 minutes. Before analysis of urine samples, it was mixed properly by turning up and down gently and catalogue has been maintained for sample information with proper coding. Processing of urine sample and Identification of Urine culture: Urine culture was prepared on HiChrome UTI Agar (Himedia, India), $5 \%$ sheep blood agar \& MacConkey agar. ${ }^{18}$ The culture plates were incubated at $37^{\circ} \mathrm{C}$ for 48hours under aerobic conditions. Culture plates having significant pure growth and colony count $\geq 10^{5} \mathrm{CFU} / \mathrm{ml}$ was considered as standard. ${ }^{19}$ The culture plates showing less than $10^{5} \mathrm{CFU} /$ $\mathrm{ml}$ colony count was repeated for further urine culture with complete history. Similarly lower colony counts with symptomatic cases were also kept in the study. ${ }^{20}$ Bacterial isolates were identified by Gram staining, motility testing and through various biochemical tests i.e. indole test, citrate test, oxidase test, catalase test, test for $\mathrm{H}_{2} \mathrm{~S}$ production, assay of lysine decarboxylase, lactose fermentation test, hydrolysis of urea, test for gas generation, coagulase test, and mannitol test as per the standard protocol. ${ }^{21}$

\section{Antimicrobial susceptibility test}

Clinical isolates were subjected for antimicrobial challenges for their susceptibility and performed as per the modified Kirby Bauer's disc diffusion method ${ }^{22}$ against standard antibiotics i.e. nitrofurantoin $(300 \mu \mathrm{g})$, ampicillin $(10 \mu \mathrm{g})$, cotrimoxazole $(25 \mu \mathrm{g})$, ofloxacin $(5 \mu \mathrm{g})$, gentamicin
$(10 \mu \mathrm{g})$, amikacin $(30 \mu \mathrm{g})$, nalidixic acid $(30 \mu \mathrm{g})$, cefuroxime $(30 \mu \mathrm{g})$, ciprofloxacin $(10 \mu \mathrm{g}) \&$ cefaclor $(30 \mu \mathrm{g})$. Suspension culture of bacteria was prepared in saline solution and turbidity was maintained and adjusted to match the standard 0.5 on McFarland scale. ${ }^{23}$ Mueller-Hinton agar plates were used for antimicrobial susceptibility testing and the uniform bacterial suspension was spread on MHA plates and discs of antibiotics were gently kept on the culture spread agar surface, at a minimum distance of $25 \mathrm{~mm}$ from each other. Bacterial strains in spreaded plated were allowed to grow for $18-24$ hours at $37^{\circ} \mathrm{C}$, aerobically. ${ }^{24}$ The zones of inhibition around each disc were measured and compared with the zone diameter as per the standards of the clinical laboratory standards institute (CLSI) guidelines. ${ }^{25}$

Escherichia coli 10974 was obtained from Deutsche Sammlung von Mikroorganismen und Zellkulturen GmbH (DSMZ), Germany. Enterococcus feacalis 51299, Klebsiella pneumonia 7500603, Staphylococcus aureus 25923 were collected from American Type Culture Collection (ATCC), USA. These cultures were used as controls for the interpretation of antibiotic sensitivity test (AST).

\section{Statistical analysis}

The results were analyzed statistically with IBM Statistical package for social sciences (SPSS) 20. The continuous variables (age distribution) had been presented as mean \pm SD and categorical variables (clinical symptoms) as number (\%). The Mann-Whitney $U$ test was performed to compare between two age groups and Pearson's chi-square test was used to compare the categorical variables.

\section{RESULTS}

The distribution of age in the patients in the sample was set within $20-65$ years. A total of 766 urine samples collected were analyzed for UTI of women reported in OPD, out of which $323(42.1 \%)$ samples were determined as culture-positive with significant bacteriuria. As per the age group distribution among participants, the calculated Mean $\pm S D$ in UTI positive cases were found to be $33.06 \pm 9.40$, whereas in UTI negative cases Mean \pm SD calculated were $35.79 \pm 12.14$ $(p<0.031)$ (Fig. 1).

In symptomatic women, various clinical symptoms were found such as burning and 
itching during urination with abnormal vaginal discharge, genital sores, and cloudy urine which were determined as 226 (69.97\%), 146 (45.20\%), $31(9.60 \%)$, and $79(24.46 \%)$, respectively. The symptoms of burning and itching during urination was the most frequently reported symptom (69.97\%) followed by abnormal vaginal discharge $(45.20 \%)$ and presence of the cloudy urine $(24.46 \%)$. The difference was found to be statistically significant both in burning and itching during urination $\left(p<0.001, \chi^{2}\right.$ test $)$ and abnormal vaginal discharge $\left(p<0.012, \chi^{2}\right.$ test) when compared to without UTI (Fig. 2).

A total of 323 bacterial uropathogens have been isolated as bacteriuria positive from urine samples. E. coli were observed to be the dominant bacterial species among all the isolated uropathogens with $54.79 \%$ rate of prevalence. The second most prevalent isolate found was Staphylococcus sp. with $22.6 \%$ followed by Enterococcus sp. with (17.64\%), and Klebsiella sp. with the lowest prevalence rate of $4.95 \%$ (Fig. 3).

The pattern of antibiotic resistance showed the differential distribution of resistance and susceptibility towards antimicrobial agent for the uropathogens. Among all nalidixic acid showed the highest resistant 160 (90.39\%) by $E$. coli and $48(65.75 \%)$ by Staphylococcus sp. The second most resistant antibiotic was Ampicillin

Table 1. Antimicrobial Resistance Pattern

\begin{tabular}{lcccc}
\hline \multicolumn{5}{c}{ Antimicrobial Resistance Pattern of Uropathogens [n=323] } \\
\hline $\begin{array}{l}\text { Antimicrobial } \\
\text { agent }\end{array}$ & $\begin{array}{c}\text { E.coli } \\
(\mathrm{n}=177) \mathrm{R} \%\end{array}$ & $\begin{array}{c}\text { Staphylococcus sp. } \\
(\mathrm{n}=73) \mathrm{R} \%\end{array}$ & $\begin{array}{c}\text { Klebsiella sp. } \\
(\mathrm{n}=16) \mathrm{R} \%\end{array}$ & $\begin{array}{c}\text { Enterococcus sp. } \\
(\mathrm{n}=57) \mathrm{R} \%\end{array}$ \\
\hline Nitrofurantoin & $21(11.8)$ & $8(10.95)$ & $2(12.5)$ & $99(15.78)$ \\
Ampicillin & $141(79.6)$ & $41(56.16)$ & $15(93.75)$ & $36(63.15)$ \\
Co-trimoxazole & $103(58.19)$ & $30(41.09)$ & $11(68.75)$ & $22(38.59)$ \\
Ofloxacin & $77(43.5)$ & $13(17.80)$ & $7(43.75)$ & $10(17.54)$ \\
Gentamicin & $39(22.0)$ & $21(28.76)$ & $3(18.75)$ & $9(15.78)$ \\
Amikacin & $36(20.03)$ & $11(15.06)$ & $2(12.50)$ & $11(19.29)$ \\
Nalidixic acid & $160(90.39)$ & $48(65.75)$ & $16(10.0)$ & $55(96.49)$ \\
Cefuroxime & $33(75.1)$ & $30(41.09)$ & $6(37.5)$ & $34(59.64)$ \\
Ciprofloxacin & $102(57.6)$ & $18(24.65)$ & $9(56.25)$ & $10(17.54)$ \\
Cefaclor & $112(63.27)$ & $30(41.09)$ & $10(62.5)$ & $21(36.84)$ \\
\hline
\end{tabular}

[Table showing patterns of antimicrobial resistance patterns by uropathogens, R\% -Resistance rate, (Percentages represent resistant isolates/total number of isolates tested)].

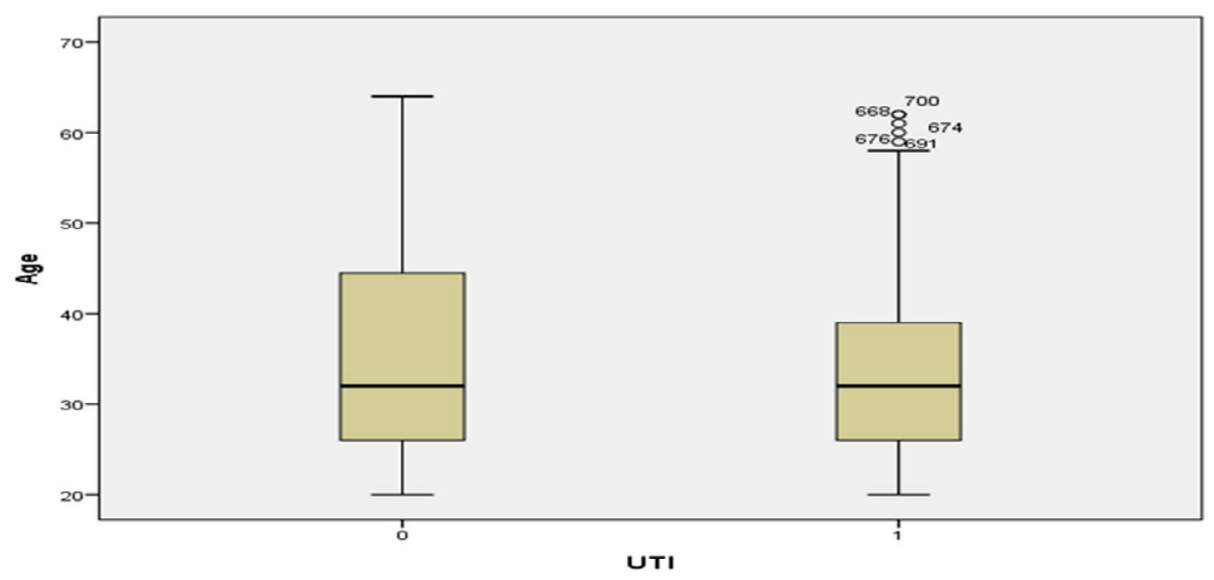

*Values are mean \pm SD of three replicates

Fig. 1. Age distribution of Urinary Tract Infection women recruited at capital hospital ( $N=766)$. 
(79.6\%) in the case of E.coli followed by cefaclor (63.27\%); however, the most sensitive drug against E.coli was observed to be nitrofurantoin with $21(11.8 \%)$ followed by cefuroxime $33(75.1 \%)$, amikacin 36 (20.03\%) and gentamicin 39 (22.0\%). Similarly, Staphylococcus sp. were sensitive against nitrofurantoin 8 (10.95\%)followed by amikacin $11(15.06 \%)$ and ofloxacin 13 (17.80\%). Nalidixic acid was shown to be the highest resistant with $16(100.0 \%)$ followed by ampicillin 15 (93.75\%), whereas nitrofurantoin and amikacin were found to be the most sensitive drug with $2(12.5 \%)$ by Klebsiella sp.

Enterococcus sp. displayed resistance against nalidixic acid and ampicillin with 55 (96.49\%) \& 36 (63.15\%) respectively, whereas nitrofurantoin and gentamicin were found to be a sensitive drug with 9 (15.78\%) (Table 1).

\section{DISCUSSION}

Due to the scarcity of reports of UTIs in non-pregnant women in the state of Odisha, India. The present investigation provides information to determine the prevalence of UTI in nonpregnant women and their antimicrobial resistant pattern. The present investigation illustrates the important data towards evaluation of antimicrobial resistance status with predominant uropathogens to deliver efficient treatment in the healthcare sector. Globally, a variety of bacterial pathogens are known to cause UTI which includes E.coli, Klebsiella, Enterobacter, Proteus, Pseudomonas, Staphylococcus, Streptococcus and Enterococcus. ${ }^{26,27}$ The present study reveals that prevalence of UTI in non-pregnant women was found to be $42.1 \%$ and the rate of prevalence was observed to be higher in our study when compared with studies conducted in Jaipur (17.19\%) and in Aligarh (10.86\%), India. ${ }^{28,29}$ whereas similar study with Mexican population showed higher rate of prevalence in uropathogens (97.3\%). ${ }^{30}$ In a ten year surveillance study conducted during 2000 to 2009 at Aveiro district of Portugal, the incidence of UTI (78.5\%) had been reported for elderly women, where more than half of the population had been infected with E. coli. ${ }^{3}$ The variation in rate of prevalence in UTI by causative uropathogens may be due to different geographical locations. This variation may also be influenced by certain local factors such as population density, social hygiene and practices. Similarly, the proximity of urethral meatus to anus, intercourse and short urethral

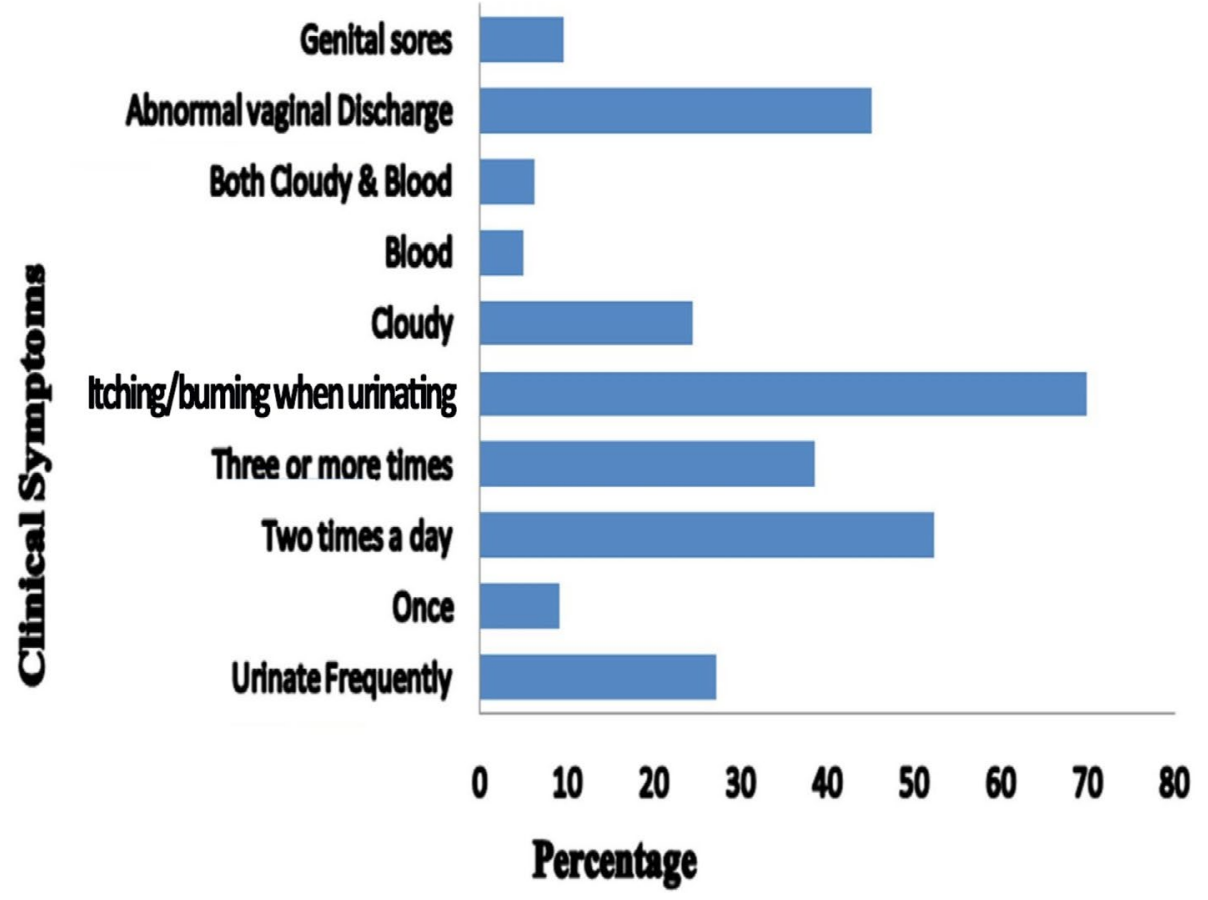

Fig. 2. Clinical symptoms in Urinary Tract Infection women recruited at capital hospital. 
feature has also been reported for higher degree of prevalence of UTI in females. ${ }^{31}$

In this study, it was observed that symptoms like Itching/ burning was significantly higher (69.97\%) during urinating followed by vaginal discharge and cloudy urine. However, the data were extrapolated from self-reported symptoms, used for cross-sectional study, where the most common symptoms described was abnormal vaginal discharge with itching sensation of the genitalia. ${ }^{32}$

Globally E.coli has been demonstrated as most the potential bacterial pathogen found in UTI. In our study, out of four pathogens, E.coli amongst the gram-negative bacilli with $54.79 \%$ was the predominant bacterial pathogen responsible for the development of urinary tract infection. This result correlates with other studies in Uganda where E.coli was isolated with $57 \%{ }^{23}$ and in Africa, the infection was in between $40-46 \% .{ }^{33} \mathrm{~A}$ similar work carried out for evaluation of predominant uropathogens by Costa et al, ${ }^{34}$ reported $E$. coli (76.8\%) as most frequent followed by Klebsiella sp. (11.3\%), Enterococcus sp. (6.2\%), and Proteus mirabilis (4.6\%) in an ambulatory service during 2011 to 2014 towards empirical treatment with fist line recommended drugs by European Association of Urology (EAU). ${ }^{34}$ Similarly, Staphylococcus sp. amongst the gram-positive bacilli was the second most dominant organism, accounting for $22.6 \%$ of isolates. Our results also correlate for Staphylococcus sp., where it has been reported as the second most abundant organism causing UTI. ${ }^{35,36}$ The pathogenesis of Staphylococcus sp. in uncomplicated UTIs had been reported as diagnostic guidelines by EAU (2014) with 5-10\% abundance in aetiolocal spectrum after $E$. coli (7095\%). ${ }^{37}$ The other isolates in this study included Enterococcus sp.(17.64\%) and Klebsiella sp. (4.95\%). It was similar to the previous studies in Uganda at Mulago Hospital by Mwaka et al who had isolated the Enterococcus sp. and Klebsiella sp. with $15 \%$ and $5 \%$ rate of infection, respectively. ${ }^{23}$

In this research, predominant bacterial pathogen E.coli have shown a high level of resistance towards commonly used $\beta$-lactams antibiotics (i.e. ampicillin and cefaclor), fluoroquinolones (i.e. ciprofloxacin and ofloxacin) co-trimoxazole, nalidixic acid and cefuroxime. A similar study conducted at six European countries including Russia for antimicrobial resistance had been reported for highest rate of resistance shown by $E$. coli against ampicillin (39.6\%), followed by trimethoprim (23.8\%), ciprofloxacin (15\%), where nitrofurantoin and fosfomycin were found to be most active drug with low resistance $(1.2 \%$ and $1.3 \%$ ), respectively. ${ }^{38}$ It showed the similar pattern of resistance previously reported in a community-based study in India. ${ }^{39}$ It may be due to the frequent misuse of antimicrobial agents in administration and disposal, which is responsible for the emergence of resistant in these strains. Thus, the finding narrates for the appropriate mode of treatment with these antibioticsby the clinicians and physicians.

The drugs like Aminoglycosides (i.e. gentamicin with $22.0 \%$ and amikacin with $20.03 \%$ ) when treated to the culture of $E$. coli showed low rate of resistance, with better sensitivity rates. Similarly, these uropathogens showed a high

\section{Percentage of microrganism causing UTI}

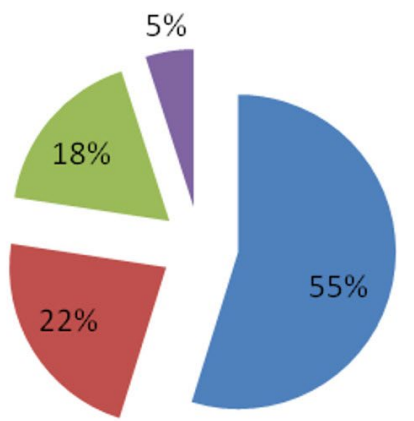

E.coli

- Staphylococcus sp.

Enterococcus sp.

Klebsiella sp.

Fig. 3. Microorganism causing UTI in women of age group 20-65. 
rate of sensitivity towards different antimicrobial agents where nitrofurantoin is the single most efficient antibiotic amongst other commonly been used in Capital Hospital against all isolated uropathogens, with a lower rate of resistant as low as $11.8 \%$ against $E$. coli. This result compares well with earlier studies conducted in different parts of India. ${ }^{29,40}$ Thus, in treatment of uncomplicated urinary tract infection, nitrofurantoin could be the preferred choice of antibiotic for recommendation by the clinicians. However, there is a limitation of orally accessible nitrofurantoin formulation for patients with systemic involvement and serious upper UTI. ${ }^{4}$ The major limitations in our findings include difficulties in rationalization and representation of antimicrobial resistance patterns of uropathogens in wider population in the Indian subcontinent since this was a hospital-based study where only women attending the Obstetrics and Gynecology departments consented to participate in the study, and provided the urine samples. Similarly, the most challenging aspects of clinically prescribed drugs are the development of resistance with prolong course of treatment in UTI patients resulting in a threat towards multidrug resistance uropathgens. Moreover, the resistance/ sensitivity changes as the year progresses since our study is five years old. Since the development of drug resistance among pathogens of urinary tracts is a process of evolving adaptation, surveillance with proper monitoring of patients treatment regimes should be conducted routinely by clinicians for effective treatment.

\section{CONCLUSION}

Amidst the paucity of reports about UTI, this study is the first of its kind that has been conducted with non-pregnant women for determining UTI incidences which includes the impact of age on its occurrence along with their mode of resistance. Although the development of drug resistance in bacteria is nearly impossible to stop, since it has gradual process of adaptation to various extreme conditions towards survival, sharing of information on change in pattern of resistance with regular monitoring to the physician can prove to be impactful in treating UTIs. This study will help in monitoring the status of antimicrobial resistance pattern among bacterial pathogens causing UTI in non-pregnant women and to upgrade the treatment regimen suitable for a particular geographical location simultaneously with individualistic approach vis-a-vis. Besides this, the study will provide an insight into the rate of prevalence of uropathogens and their pattern of resistance in non-pregnant womens of the clinical setting which can be comparable to other regions of the country as well as to the world.

\section{ACKNOWLEDGMENTS}

The authors are thankful to the Director and Institutional Ethics Committee, Asian Institute of Public Health, Bhubaneswar for permission to carry out the investigation. DS gratefully acknowledges the Department of Higher Education, Government of Odisha (Grant No. 26913/HED/HE-PTC-WB-02-17/OHEPEE) for infrastructure development to Centre of Excellence in Environment and Public Health, Ravenshaw University, Cuttack. All the study participants are duly acknowledged for their voluntary participation in this study.

\section{CONFLICT OF INTEREST}

The authors declare that there is no conflict of interest.

\section{AUTHORS' CONTRIBUTION}

DS and BP conceptualized and designed the study, did data analysis and prepared the manuscript. PD collected clinical data instruments and data analysis. JRM conducted the laboratory experiments. AP and SJ drafted and edited the manuscript. All authors read and approved the final manuscript for publication.

\section{FUNDING}

None.

\section{DATA AVAILABILITY}

All datasets generated or analyzed during this study are included in the manuscript.

\section{ETHICS STATEMENT}

This study has been approved by the Institutional Ethics Committee, Asian Institute of Public Health (AIPH), Bhubaneswar, Odisha, India. (AIPH ethics ref: ERC/ No: 2015-09). 


\section{REFERENCES}

1. Gonzalez CM, Schaeffer AJ. Treatment of urinary tract infection: what's old, what's new, and what works. World J Urol. 1999;17(6):372-382. doi: 10.1007/ s003450050163

2. Rock W, Colodner R, Chazan B, Elias M, Raz, R. Ten years surveillance of antimicrobial susceptibility of community-acquired Escherichia coli and other uropathogens in northern Israel (1995-2005). The Isr Med Assoc J. 2007;9(11):803-805. PMID: 18085038

3. Linhares I, Raposo T, Rodrigues A, Almeida A. Frequency and antimicrobial resistance patterns of bacteria implicated in community urinary tract infections: a ten-year surveillance study (2000-2009). BMC Infect Diseases. 2013;13(19):1-14. doi: 10.1186/1471-233413-19

4. Vasquez $Y$, Hand WL. Antibiotic susceptibility patterns of community acquired urinary tract infection isolates from female patients on the US [Texas]-Mexico Border. Journal of Applied Research. 2004;4(2):321-326.

5. Griebling TL. Urinary tract infection in men. In Litwin MS, Saigal CS, Edn. Urology Diseases in America, Washington, D.C, GPO; 2007: 621-45.

6. Pranandari R, Supardi S, Andrajati R.Parenteral antibiotic usage patterns and effects of intravenous to oral switching on the length and cost of hospitalization. International Journal of Applied Pharmaceutics. 2017;9(Spl. Issue):85-89. doi: 10.22159/ijap.2017. v9s1.44_50

7. Deepika M, Nashima K, Rajeswari S. Antimicribial activity of panchacavya against Urinary Tract Infection. Int J Curr Pharm Res. 2016; 8(3):68-70.

8. Zelikovic I, Adelman RD, Nancarrow PA. Urinary tract infections in children. An update. West J Med. 1992;157:554-561.

9. Sobel JD, Kaye D. Urinary tract infections. In Mandell GL, Bennett JE, Dolin R(eds).Mandell, Douglas and Bennett's Principles and Practice of Infectious Diseases. $7^{\text {th }}$ Ed. Churchill Livingstone, Philadelphia, USA. 2010:957-985. doi: 10.1016/B978-0-443-068393.00069-2

10. Prakasam KCA, Kumar KGD, Vijayan M. A cross sectional study on distribution of urinary tract infection and their antibiotic utilization pattern in Kerala. Int J Res Pharm Biomed Sci. 2012;3:1125-1130.

11. Warren JW, Tenney JH, Hoopes JM, Muncie HL, Anthony WC. A prospective microbiologic study of bacteriuria in patients with chronic indwelling urethral catheters. J Infect Dis. 1982;146:719-723. doi: 10.1093/infdis/146.6.719

12. Foxman B, Brown P. Epidemiology of urinary tract infections: transmission and risk factors, incidence, and costs. Infect Dis Clin North Am. 2003;17(2):227-241. doi: 10.1016/S0891-5520(03)00005-9

13. Blondeau JM. Current Issues in the Management of Urinary Tract Infections: Extended-Release Ciprofloxacin as a Novel Treatment Option. Drugs. 2004;64(6):611-628. doi: 10.2165/00003495200464060-00004

14. Salunke GV, Gidamudi SS. Antibiotic susceptibility of bacterial strains, with special reference to Escherichia coli isolated from urinary tract infections in rural
Maharashtra. Asian J Pharm Clin Res. 2017;10(1):202205. doi: 10.22159/ajpcr.2017.v10i1.14871

15. Wilson ML, Gaido L. Laboratory Diagnosis of Urinary Tract Infections in Adult Patients. Clin Infect Dis. 2004;38:1150-1158. doi: 10.1086/383029

16. Bonadio M, Meini M, Spetaleri P,Gilgi C. Current microbiological and clinical aspects of urinary tract infections. Eur J Urol. 2001;40(4):439-445. doi: 10.1159/000049813

17. Mathai D, Jones RN, Pfaller MA. Epidemiology and frequency of resistance among pathogens causing urinary tract infection in 1,510 hospitalized patients: a report fromthe SENTRY Antimicrobial Surveillance Program [North America]. Diag Microbiol Infect Dis. 2001;40(3):129-136. doi: 10.1016/S07328893(01)00254-1

18. Akter ML, Haque R, Salam MA. Comparative evaluation of chromogenic agar medium and conventional culture system for isolation and presumptive identification of uropathogens. Pak J Med Sci. 2014;30(5):1033-1038. doi: $10.12669 /$ pjms.305.5243

19. Hinmann F. The meaning of significant bacteriuria. JAMA. 1963;184(9):727-728. doi: 10.1001/ jama.1963.03700220103025

20. Das A, Banerjee T. Prevalence of Urinary Tract Infections and Susceptibility Pattern of Uropathogens in Women of Reproductive age Group from North India. Journal of Advances in Medicine. 2015;4(1-2):59. doi: 10.5958/2319-4324.2015.00002.4

21. Win WC, Stephen DA, Stephen A, Janda W, Koneman EW, Schrehrenberg P. Koneman's Color Atlas and Textbook of Diagnostic Microbiology. $6^{\text {th }}$ Ed. 2005.

22. Bauer AW, Kirby WMM, Sherris JC, Truck M. Antibiotic susceptibility testing by a standardized single disk method. Am J Clin Pathol. 1966;45(4):493-496. doi: 10.1093/ajcp/45.4_ts.493

23. Mwaka AD, Mayanja-Kizza H, Kigonya E, KadduMulindwa D. Bacteriuria among adult non pregnant women attending Mulago hospital assessment centre in Uganda. Afr Health Sci. 2011;11(2):182-189. PMCID: PMC3158526

24. Goyal S, Beniwal V. Study of Multidrug Resistance Pattern among Escherichia coli Isolated From Patients with Urinary Tract Infection. Asian J Pharm Clin Res. 2016;9(6):157-160. doi: 10.22159/ajpcr.2016. v9i6.13961

25. Cockerill FR, et al. Clinical and Laboratory Standards Institute. Performance Standards for Antimicrobial Susceptibility Testing, 21st Informational Supplement. CLSI Document M100-S21. Clinical and Laboratory Standards Institute, Wayne, Pa 2011. https:// vchmedical.ajums.ac.ir/_vchmedical/documents/ CLSI\%202011.pdf

26. Nicolle LE. Epidemiology of urinary tract infection. Infect Med. 2001;18:153-162.

27. Gorbach SL, Bartlett JG, Blacklow NR. (eds) Infect Dis. Philadelphia: Lippincott Williams \& Wilkins, 2004.

28. Akram M, Shahid M, Khan AU. Etiology and antibiotic resistance patterns of community-acquired urinary tract infections in J N M C Hospital Aligarh, India. Ann Clin Microbiol Antimicrob. 2007;6:4. doi: 10.1186/1476-0711-6-4 
29. Sood S, Gupta R. Antibiotic resistance pattern of community acquired uropathogens at a tertiary care hospital in Jaipur, Rajasthan. Indian J Community Med. 2012;37(1):39-44. doi: 10.4103/0970-0218.94023

30. Garcia-MoruaA, Hernandez-Torres A, Salazar-de-Hoyos $\mathrm{JL}$, Jaime-Davila RL, Gomez-Guerra LS. Community acquired urinary tract infection etiology and antibiotic resistance in a Mexican population group. Revista Mexicana deUrologia. 2009;69:45-48.

31. Omoregie R, Erebor JO, Ahonkhai I, Isobor JO, Ogefere HO. Observed changes in the prevalence of uropathogens in Benin City, Nigeria. NZJ Med Lab Sci. 2008;62:29-31.

32. Sumpter C, Torondel B. A systematic review of the health and social effects of menstrual hygiene management. PLoS One. 2013;8(4):e62004. doi: 10.1371/journal.pone.0062004

33. Kayima JK, Otieno LS, Twahir A, Njenga E. Asymptomatic bacteriuria among diabetics attending Kenyatta National Hospital. East Afr Med J. 1996;73(8):524-526.

34. Costa T, Linhares I, Ferreira R, Neves J, Almeida A. Frequency and antibiotic resistance of bacteria implicated in community urinary tract infections in North Aveiro between 2011 and 2014. Microb Drug Res. 2018;24(4):493-504. doi: 10.1089/mdr.2016.0318
35. Orret FA,Davis GK. A comparison of antimicrobial susceptibility profile of urinary pathogens for two years,1999 and 2003. West Indian MedJ. 2006;55(2):9599. doi: 10.1590/S0043-31442006000200006

36. Nerurkar A, Solanky P, Shanta SN. Bacterial pathogens in urinary tract infection and antibiotic susceptibility pattern. J Pharm Biomed Sci. 2012;21:1-3.

37. Garbe M, Bjerklund-Johansen TE, Bartoletti R, et al. Guidelines on urological infections, European Association of Urology, 2014. https://uroweb.org/ wp-content/uploads/19-Urological-infections_LR.pdf

38. Ny $S$, Edquist $P$, Dumpis $U$, et al. Antimicrobial resistance of Escherichia coli isolates from outpatient urinary tract infections in women in six European countries including Russia. J Global Antimicrob Res. 2019;17:25-34. doi: 10.1016/j.jgar.2018.11.004

39. Kothari A, Sagar V. Antibiotic resistance in pathogens causing community-acquired urinary tract infections in India: A multicenter study. J Infect Dev Ctries. 2008;2(5):354-358. doi: 10.3855/jidc.196

40. Shaifali I, Gupta U, Mahmood SE, Ahmed J. Antibiotic susceptibility patterns of urinary pathogens in female outpatients. N Am J Med Sci. 2012;4(4):163-169. doi: $10.4103 / 1947-2714.94940$ 